Billedo, C. J., Kerkhof, P., \& Finkenauer, C. (2020). Facebook intensity, social network support, stability and satisfaction in longdistance and geographically-close romantic relationships: A test of a mediation model. Cyberpsychology: Journal of Psychosocial Research on Cyberspace, 14(2), Article 5. https://doi.org/10.5817/CP2020-2-5

\title{
Facebook Intensity, Social Network Support, Stability and Satisfaction in Long-Distance and Geographically-Close Romantic Relationships: A Test of a Mediation Model
}

\author{
Cherrie Joy Billedo ${ }^{1}$, Peter Kerkhof ${ }^{2}, \&$ Catrin Finkenauer ${ }^{3}$ \\ ${ }^{1}$ University of Amsterdam, Amsterdam, Netherlands \\ 2 Vrije Universiteit Amsterdam, Amsterdam, Netherlands \\ 3 Utrecht University, Utrecht, Netherlands
}

\begin{abstract}
The impetus for this study is the proposition that social network sites (SNSs), like Facebook, can be beneficial for romantic relationships via network support functions. This study investigated a model which proposes that the use of Facebook predicts relationship support from Facebook connections, and this, in turn, predicts relationship stability and satisfaction in romantic relationships. This mediation model was tested on data gathered via an online survey among individuals who use Facebook, who are in long-distance (LDRR, $n=142$ ) and geographically-close romantic relationships (GCRR, $n=314)$. GCRR participants reported higher levels of Facebook intensity and relationship support, as well as perceived relationship stability and satisfaction than participants in LDRR. Moreover, the results indicated that Facebook intensity predicted higher access to Facebook relationship support in LDRR and GCRR which, in turn, predicted perceived relationship stability and satisfaction in LDRR; and only perceived relationship satisfaction in GCRR. However, Facebook intensity had direct negative impacts on relationship satisfaction in GCRR, and on perceived relationship stability in LDRR. Facebook intensity and Facebook relationship support were not associated with relationship stability in GCRR. This demonstrates the relative importance of SNSs, such as Facebook, in relationship stability for those in LDRR.
\end{abstract}

Keywords: Social network sites; Facebook, romantic relationships; network support; relationship satisfaction; relationship stability

\section{Introduction}

Communication technologies may play an important role in maintaining and nurturing existing relationships. Romantic partners concurrently use various communication platforms with affordances that serve different or overlapping functions for relational maintenance. Relational maintenance involves keeping a relationship stable and ensuring that the relationship is mutually satisfying for partners (Tong \& Walther, 2011). In geographically-close romantic relationships (GCRR), communication technologies may be used as a supplement to face-to-face interaction (Rabby \& Walther, 2003). In long distance romantic relationships (LDRR), however, the use of communication technologies may be more crucial. LDRR often require more effort to maintain compared to GCRR (Aylor, 2003). Communication technologies may help mitigate the adverse effects of distance in LDRR (Billedo et al., 2015; Dainton \& Aylor, 2002; Jiang \& Hancock, 2013).

Maintaining a romantic relationship does not only involve the romantic partners themselves but also a network of people who may provide information and support (Canary \& Stafford, 1992; Cox et al., 1997; Felmlee, 2001; Visser et al., 2017). Among the various communication technologies, social network sites (SNSs), like Facebook, have both private and public affordances which may facilitate couples' access to their social network. Access to a social network implies that couples may send and gather information from their SNSs network connections, making it possible to receive support (Ellison et al., 2014; Utz \& Breuer, 2017). Thus, we argued that SNSs, in this study Facebook, are relevant for romantic relationships not only via interpersonal aspects (e.g., direct communication between partners), but also via social aspects, such as communication with a network of family and friends who may provide support to one's romantic relationship. 
One of the reasons for the use of communication technologies, like SNSs, for relational maintenance is because they reduce transaction costs (Tong \& Walther, 2011). These platforms have affordances that are believed to reduce the amount of effort or cost of maintaining relationships. Similar to other forms of computer-mediated communication (e.g., Skype, Whatsapp, SMS, Email), SNSs, like Facebook, have one-on-one communication affordances that allow direct interaction between partners. What makes SNSs unique is that they also provide a public and social context for interaction between partners and their social network. On SNSs, couples are able to observe their partner in a public context. SNSs also provide couples opportunities for relationship presentation and open up the relationship to a social network for possible scrutiny and evaluation (Tong \& Walther, 2011; Utz \& Beukeboom, 2011). When people connect with family and friends on SNSs, they may make relationship-related information "public". According to Tong and Walther (2011), it is the combination of having private and public communications in platforms like SNSs that has the potential to transform the way people maintain relationships. The private and public aspects of SNSs make relational maintenance not just an interpersonal process between couples, but also a social process that involves the social network of both partners.

So far, studies on the social aspects of SNSs use in romantic relationships focused on two types of impacts: First, the impact of SNSs public, indirect communication (e.g., browsing the partner's SNSs wall) on couple members themselves (Fox \& Warber, 2013; Muise et al., 2009; Tokunaga, 2011; Utz \& Beukeboom, 2011); and, second, the impact of SNSs relationship public presentation (e.g., SNSs display of relationship status, couple profile pictures, relationship-related status updates) on couple members themselves (Papp et al., 2012; Saslow et al., 2013), and on couple's social network members (Emery et al., 2015). These studies point to the value of SNSs use in romantic relationships involving not only the couples but also members of their social networks. Via the social aspects of SNSs, couple members are able to make their posts on each other's walls accessible to their network. Additionally, posts of a couples' network on their walls are visible to their partner. These social affordances could prove particularly relevant for those in LDRR, considering that they might have geographically separated social networks, or one of them is away from their established support networks (Weiner \& Hannum, 2013). In GCRR, relationship-related social network processes on SNSs might play a supplementary role to offline processes (Tong \& Walther, 2011). In this study, we aimed to extend research by clarifying the relevance of SNSs in LDRR and GCRR on account of relationship support from couples' social networks.

\section{The Direct Impact of Facebook Use on Romantic Relationship Outcomes}

Considering both private and public communication affordances, it is relevant to assess the impact of SNSs on relationship outcomes (Fox et al., 2013). In this study, we aimed to investigate how couple members assess the impact of SNSs, particularly Facebook, on their relationships. We focused on Facebook because it is currently the most popular SNS (Ahmad, 2019). Earlier studies have established that Facebook is deliberately used for romantic relationship maintenance in both LDRR and GCRR (Billedo et al., 2015; Dainton \& Stokes, 2015).

The results of previous investigations on the associations of Facebook use with relationship outcomes are inconsistent. In a couple of studies, Facebook use was associated with negative outcomes such as conflicts (Clayton et al., 2013) and increased jealousy (Muise et al., 2009; Utz \& Beukeboom, 2011). In other studies, however, Facebook use was associated with increased relationship satisfaction (Saslow et al., 2013; Utz \& Beukeboom, 2011). There were also studies showing a lack of association of Facebook use with intimacy and relationship satisfaction (Hand et al., 2013; Kirk, 2013). One reason for the lack of consistency among these studies may be the difficulty of isolating the impacts of various social processes on Facebook (e.g., partner surveillance, network support) (Billedo et al., 2015; Fox \& Warber, 2013; Muise et al., 2009; Tokunaga, 2011; Utz \& Beukeboom, 2011). In this study, we aimed to clarify these conflicting findings by examining the impact of Facebook use on relationship outcomes, while accounting for the contribution of relationship support from couples' networks on Facebook. We expected that Facebook use could predict better relationship outcomes because of the network support. Consistent with Billedo et al.'s (2015) previous study on the role of Facebook in romantic relationships, we conceptualized Facebook use as Facebook intensity, which includes duration of use, network size, and integration of Facebook into one's life. Facebook intensity has a better predictive validity compared to other measures of Facebook use (e.g., active and passive Facebook use measures) in the context of social relationships (Ellison et al., 2007; Vanden Abeele et al., 2018).

In this study, we focused on the impact of Facebook on two crucial relationship outcomes: Relationship stability (i.e., the continuation and future of the relationship) and relationship satisfaction (i.e., positive feelings about the relationship) (Felmlee, 2001; Rusbult \& Buunk, 1993; Vitak, 2014). These two outcomes are considered to be different conceptually and might have different psychological and social correlates, although they correlate empirically (Shafer et al., 2014).

According to Vitak (2014), Facebook is important for relationship outcomes because they may provide "valuable relational information that would be more difficult to obtain or would likely be delayed if it were obtained through alternate channels" (Research Questions and Hypotheses section, para. 6). Considering physical distance, it is likely that those in LDRR may be motivated to use Facebook because it allows relationship partners to maintain a sense of emotional connection and psychological propinquity with each other despite geographic separation (Billedo et al., 2015). For those in GCRR, Facebook may be perceived as a supplementary communication medium, especially in updating and sharing mundane narratives and reflections, that may 
serve maintenance functions (Tong \& Walther, 2011). Thus, we argued that Facebook intensity may predict perceived relationship stability and satisfaction. We present our first hypothesis:

H1: Facebook intensity will predict greater perceived relationship stability and satisfaction in both LDRR and GCRR.

\section{Social Network Perspective on Relationship Support}

A social network perspective on romantic relationships is based on the premise that romantic couples do not exist in a (social) vacuum, and that couples' social networks have a substantial influence on the outcome of the relationship (Felmlee, 2001). Social networks may play a facilitative or inhibitory role in relationship stability, as well as closeness and intimacy (Cox et al., 1997; Felmlee, 2001). There are three ways by which social networks may benefit relationship quality (Felmlee, 2001): Via network approval, network support, and network embeddedness. Network approval includes favorable/positive reactions in the form of direct (e.g., when a pair is told that they are a perfect match) or indirect expressions (e.g., invited together to events). Network support comprises emotional (expressions of caring), informational (advice), and instrumental forms (assistance and material aid), whereas network embeddedness involves couple members' belonging to a common network.

\section{Facebook Relationship Support}

Based on a communication perspective, social support includes "verbal and nonverbal communication...that reduces uncertainty about the situation, the self, the other, or the relationship..." (Albrecht \& Adelman, 1987, p.19). Drawing from this perspective and from a social network perspective of relationships (Felmlee, 2001), we defined Facebook relationship support as relationshiprelated supportive communication that couple members may access and receive from their networks via Facebook. We conceptualized Facebook relationship support as having four dimensions: Approval/emotional, informational, instrumental, and embeddedness. According to Felmlee (2001), there are five ways by which romantic relationships may benefit from their social network: Network approval, emotional support, informational support, instrumental support, and network embeddedness. These dimensions are consistent with existing categories of social support for individuals such as socio-emotional, informational, instrumental, and embeddedness support (Mikal et al., 2013). According to Mikal et al. (2013), socio-emotional support involves receiving acceptance/approval from others, and knowing that others are there for you. In the context of Facebook interactions, approval/emotional relationship support may pertain to favorable expressions and positive regard toward a couples' romantic relationship (e.g., receiving likes or positive comments on relationship-related posts). In this study, we combined network approval and emotional network support under the socio-emotional support dimension (Mikal et al. 2013). As for informational support on Facebook, it may be in the form of getting information and/or advice about one's partner and their relationship. Instrumental support may refer to the availability of people among their Facebook contacts whom they can ask for assistance or help when their partner is in need (e.g., having people in one's social network to assist when one is unable to provide direct help to the partner). Lastly, via Facebook, a couple's social network may provide embeddedness support or a shared sense of belonging (e.g., relationship partners having common Facebook contacts who share their attitudes and beliefs).

On Facebook, couples are able to display their relational identity (e.g., in a relationship) to their network which could impact on the way their network perceives them. Emery et al. (2015) found that couples who display their relational identity on Facebook were perceived by observers as likable. This suggests that with Facebook's social affordances, couples may lower the cost of maintaining social networks and may help manage impressions to facilitate resource exchanges, such as sharing of relevant information and conveying of emotional support (Ellison et al., 2014; Tong \& Walther, 2011). Previous studies have shown that couple members who are experiencing doubts or uncertainty about their relationship deliberately and actively gather information from their partner's Facebook activities (Fox \& Warber, 2013; Tokunaga, 2011). Consequently, couple members may also obtain and receive information and emotional support from their networks via Facebook (Muise et al., 2009; Tokunaga, 2011; Utz \& Beukeboom, 2011). Such information may help alleviate (or confirm) doubts about their partner's feelings and the future of their relationship (Billedo et al., 2015; Keneski \& Loving, 2014; Knobloch \& Solomon, 1999). Thus, Facebook may function as venues for couple members to access social capital and receive relationship support from their social networks (Ellison et al., 2014; Papacharissi \& Mendelson, 2008; Utz \& Breuer, 2017; Vanden Abeele et al., 2018). Previous studies have shown that Facebook intensity predicts individuals' social capital and social support (Ellison et al., 2014; Hu et al., 2017; Vanden Abeele et al., 2018). Similarly, Facebook intensity may predict relationship support on Facebook. Thus, we hypothesized that:

\section{H2: Facebook intensity will predict greater Facebook relationship support.}

\section{Facebook Relationship Support and Relationship Outcomes}

Social networks can be powerful in directing the outcome of a relationship (Arriaga et al., 2004). According to a social network perspective, "couples exist with systems of networks that frequently alter their interactions, affect their roles, and influence their decisions" (Felmlee, 2001, p.1260). For instance, the range of relational maintenance behaviors of couples that are associated with 
better relationship outcomes include interactions and time spent with a shared network of friends and even acquaintances (Stafford \& Canary, 1991).

A social network perspective (Felmlee, 2001), as well as the more recent social network evaluation and transmissions model (Keneski \& Loving, 2014), predict that network support and approval influence romantic relationship outcomes. The opposite hypothesis that relationship quality, specifically relational closeness, predicts network support is also plausible. However, this is particularly evident in recently initiated relationships (Arriaga et al., 2004). In ongoing relationships, network support is more likely to influence closeness and stability. Research on established relationships suggests that the effect of social support and approval on relationship quality is more robust than the reverse effect (Arriaga et al., 2004; Sinclair et al., 2014).

Access to relationship support on Facebook might provide couples with public relational experiences and processes that may serve relationship maintenance functions in both LDRR and GCRR (Billedo et al., 2015). It is likely that couple members who receive relationship support on Facebook may experience positive relationship outcomes (Vitak, 2014). Social network support via Facebook may play a facilitative role in romantic relationship stability and satisfaction in LDRR and GCRR. We predicted that:

\section{H3: Facebook relationship support will predict greater perceived relationship stability and satisfaction.}

\section{The Mediation Model}

The conceptual model for this study is presented in Figure 1. This model predicts that the association of Facebook intensity and perceived relationship outcomes is mediated by Facebook relationship support. We first tested this mediation model among individuals in LDRR. This was based on the assumption that Facebook affordances may be relatively more relevant for couples in LDRR (Billedo et al., 2015; Dainton \& Aylor, 2002; Jiang \& Hancock, 2013). However, testing the model in LDRR context alone will not help determine if the model is unique for those in LDRR. A few studies have established that Facebook are deliberately used for romantic relationship maintenance in both LDRR and GCRR (Billedo et al., 2015; Dainton \& Stokes, 2015). Thus, in this study, we aimed to compare this mediation model among individuals in LDRR and GCRR. Considering that GCRR couples have relatively more intact social networks than LDRR couples (Weiner \& Hannum, 2013), we expected that Facebook intensity would have a stronger effect on Facebook relationship support among those in LDRR than those in GCRR. Moreover, since distance, and its inevitable consequence of limited physical togetherness, may threaten the continuation of the relationship and satisfaction of romantic partners (Mok et al., 2007), we also expected that Facebook intensity and Facebook relationship support would have stronger effects on relationship outcomes in LDRR than in GCRR. Thus, we hypothesized that:

H4a: The impact of Facebook intensity on Facebook relationship support and relationship outcomes will be stronger in LDRR than in GCRR.

H4b: The impact of Facebook relationship support on relationship outcomes will be stronger in LDRR than in GCRR.

\section{Covariates}

One reason for the inconsistent findings on the association of Facebook use and relationship outcomes is the difficulty of isolating the possible influences of other communication platforms. It is likely that couple members use various communication platforms along with Facebook that might have concurrent influences on their relationships (Caughlin \& Sharabi, 2013; Kirk, 2013). In investigating the mediation model, we aimed to account for the effects of other forms of communication technology that romantic partners use to communicate with each other. Moreover, we accounted for a couple of demographic factors (such as gender and age) and a relationship-related factor (length of relationship) that could influence relationship stability and satisfaction (Arriaga et al., 2004; Jackson et al., 2014; Ruffieux et al., 2014). 


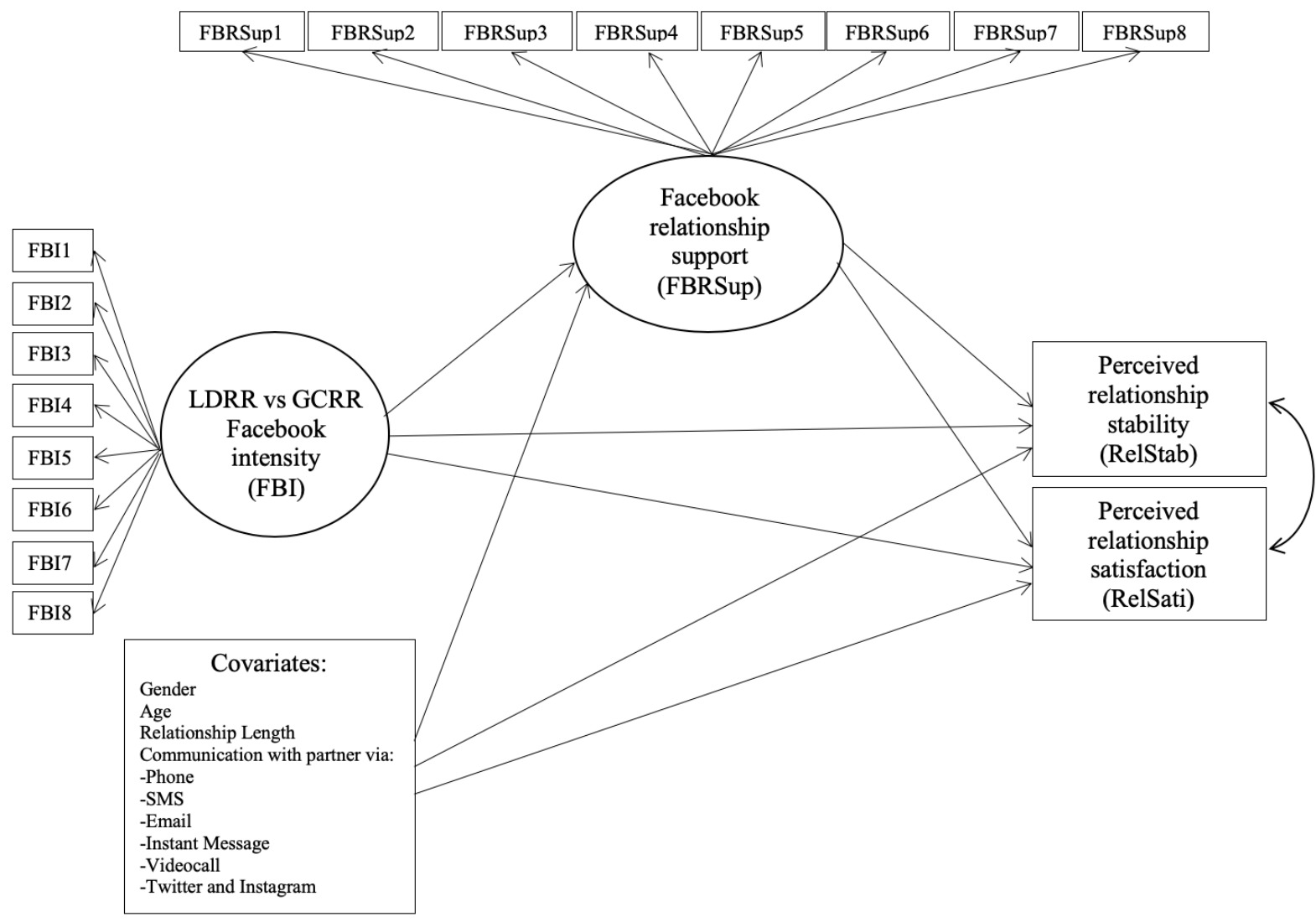

Method

\section{Participants and Procedure}

A total of 456 participants (331 women, 125 men) participated in this cross-sectional study. We recruited via Facebook by posting an announcement with a link to an online survey. For the first round of data gathering, we collected data from short-term migrants (e.g., international students, overseas workers/expats, etc.) who were in LDRR. The survey link was posted by one of the researchers and members of their network on their own Facebook pages, Facebook group pages of international students, expatriates, overseas workers, and long-distance relationships groups. To participate in the study, respondents had to indicate that they were in a long-distance romantic relationship, that they were Facebook users, and that their partner was among their Facebook contacts. We defined LDRR based on participants' self-identification (i.e., "Are you in a long-distance romantic relationship?"). This captures an individual's relational reality better compared to researcher-imposed measures (Stafford, 2005). A total of 142 participants completed the survey. The mean age of the participants was 25 years $(S D=5.05)$, with age ranging from 17 to 49 years old. On average, participants were in a relationship with their partner for 3 years (ranging from 1 month to 13 years; $M=36.20$ months; $S D=34.10)$. Among the LDRR participants, $73.1 \%(n=98)$ were exclusively dating, $11.9 \%(n=16)$ were engaged, $7.5 \%(n=10)$ were married, and $7.5 \%(n=10)$ were in an open relationship. Eight $(5.6 \%)$ participants did not indicate their relationship status.

For the GCRR comparison group, we used the same selection criteria except they had to be in a geographically-close romantic relationship to participate and should not have previously participated in the same study. For the GCRR group, the link was posted on the researcher's and their networks' Facebook pages, public Facebook group pages such as universities, organizations, and various interest groups. There were 314 participants who completed the survey. The mean age of participants in GCRR was 29 years $(S D=6.74)$, with age ranging from 19 to 70 years old. The length of GCRR relationships was, on average, 5 years (ranging from 1 month to 29 years; $M=65.15$ months; $S D=66.43)$. For the GCRR participants, $59.7 \%(n=187)$ were exclusively dating, $8.9 \%$ $(n=28)$ were engaged, $27.2 \%(n=85)$ were married, and $4.2 \%(n=13)$ were in an open relationship. One (0.3\%) participant did not put their relationship status. The time interval between data collections was approximately one year, LDRR data in 2015 and GCRR data in 2016. Both rounds took approximately two weeks. The study was approved by the Research Ethics Review Committee of the university where it was conducted. In answering the survey, the participants were assured of anonymity and were informed that they can quit anytime with no consequences. In both LDRR and GCRR data collection, participation was voluntary. The participants did not receive any form of compensation for participating in the study. 


\section{Measures}

This study was part of a larger survey. Only the measures relevant to this current paper are reported here.

\section{Facebook Intensity}

We used the Facebook Intensity Scale (FBI) developed by Ellison et al. (2007) (Appendix A). This scale assesses duration of Facebook use, network size, and integration of Facebook into one's daily life. The items were measured on a 5-point Likert scale from $1=$ strongly disagree to $5=$ strongly agree (Cronbach's $\alpha=.82$ ).

\section{Facebook Relationship Support}

For this study, we developed a Facebook Relationship Support Scale (FBRSup) to measure relationship social support received by romantic partners from their social network on Facebook. We adapted existing categories of social support (i.e., approval/emotional, informational, instrumental, embedded) and created two items for each category. The items were measured on a 5 -point Likert scale from 1 = strongly disagree to $5=$ strongly agree. We asked 10 undergraduate students who were in a romantic relationship to accomplish the survey. Based on their comments, we modified one item of approval/emotional support by adding "status updates" in the statement. Please see Appendix B for the list of items.

To identify the underlying structure of the 8-item FBRSup, we conducted an exploratory factor analysis (EFA). The EFA revealed 2 main factors accounting for $57.6 \%$ of the variance. Factor 1 (items 2, 3, 4, 7, and 8) represented Facebook Support for the Couple (e.g., "My partner and I share common Facebook contacts who are supportive of our relationship"; Cronbach's $\alpha=.78$ ). Factor 2 (items 1, 5, and 6) reflected Facebook Support for a Couple Member (e.g., "When I am having difficulties communicating with my partner, I approach friends and/or family via Facebook for help"; Cronbach's $\alpha=.68$ ). Due to the low reliability of Factor 2 , all the 8 items were used as a unidimensional scale for the succeeding analyses. The 8 -item measure of FBRSup has a good reliability (Cronbach's $\alpha=.79$ ).

\section{Perceived Relationship Quality}

We assessed perceived relationship stability (RelStab) using a face-valid one-item measure: "I think my relationship with my partner is very stable" measured on a 7-point scale ranging from $1=$ strongly disagree to $7=$ strongly agree, taken from the relational uncertainty measure (Dainton \& Aylor, 2001). We measured perceived relationship satisfaction (RelSati) also with a facevalid single item: "In, general, how satisfied are you with your relationship?" measured on a 5-point scale ranging from $1=$ very low to $5=$ very high, taken from the relationship assessment scale (Hendrick, 1988).

\section{Control Variables}

To help rule out some confounding variables and to ensure that the observed effects are not artifacts of differences in other forms of communication, we also tested the theoretical model controlling for some variables: Gender, age, length of relationship (measured in years and months), and frequency of interaction with partner using various communication channels. We asked the participants to indicate for each channel how often they communicated with their partner using: Phone, SMS, email, instant messaging, video calling (Skype), and Twitter and Instagram ( $1=$ never to $5=$ very often).

\section{Facebook Communication with Partner}

We also asked the participants to indicate how often they communicated with their partner using: Facebook private message (messenger) and Facebook public communication (wall) $(1=$ never to $5=$ very often) to assess Facebook use specifically with their partners.

\section{Distance Relationship Status}

We added two items to check LDRR and GCRR self-identification of participants: "My partner lives far enough away from me that it would be very difficult or impossible for me to see him/her every day", taken from the LDR index (Pistole \& Roberts, 2011), and "My partner lives in another country", both measured on a 5-point Likert scale $(1=$ strongly disagree to $5=$ strongly agree, Cronbach's $\alpha=.80)$. 


\section{Data Analytic Plan}

We first conducted descriptive data analysis. This was followed by invariance analyses. Since our study involved two different groups (LDRR and GCRR) with data for each group collected at different time points, we wanted to ensure the integrity of the measurement instruments and establish the comparability between groups. We performed a series of analyses using multigroup confirmatory factor analysis (MCFA) based on a procedure recommended by Kühne (2013). This procedure incorporates measurement invariance testing (configural, metric, and scalar invariance) and model comparison between the groups (test of moderation). Configural invariance indicates that the groups being compared share similar meaning of the latent constructs. Metric invariance and scalar invariance are necessary to make meaningful comparisons between groups because they indicate that the latent constructs have the same meaning and that there is no systematic response bias across groups (Chen, 2008; Kühne, 2013). With metric invariance established, the strength of associations among the constructs in the model (i.e. the specified causal paths) can be compared meaningfully; while scalar invariance ensures that the amount of each of the constructs (i.e., means) in the model can be compared meaningfully (Chen, 2008).

To conduct measurement invariance testing and model comparisons, the first step is to perform a configural invariance test by estimating a baseline model for the pooled sample (configural invariance model) using MCFA. A good fit of the model to the data indicates that the meaning of the latent constructs does not differ between the two groups. The patterns of factor loadings for each of the constructs in the model are the same across the two groups, showing configural invariance. The next step is to perform a metric invariance test. A metric invariance model is estimated by constraining the factor loadings to be equal across groups. If the $\chi^{2}$ difference test shows that the metric invariance model does not differ significantly from the configural invariance model, metric invariance is supported. Having established metric invariance, the strength of associations among the constructs in the model (i.e. the specified causal paths) can be compared across LDRR and GCRR groups. Comparison of causal paths between groups are conducted using z-test. Following the metric invariance test is the scalar invariance test. For this test, the intercepts of the items are constrained to be the same across the groups. If the $\chi^{2}$ difference test indicates that the scalar invariance model does not differ significantly from the metric invariance model, then invariance is established. This ensures that the means of the constructs can be compared meaningfully across LDRR and GCRR groups.

To check global model fit, we used the following evaluation criteria (Van de Schoot et al., 2012; Vandenberg \& Lance, 2000): The ratio of the $\chi^{2}$ to its degree of freedom (where a value ranging 2.0-5.0 indicates acceptable fit); the root mean square error of approximation (RMSEA) (with a cut-off value of <.08 which indicates acceptable fit); comparative fit index (CFI) and Tucker-Lewis Index (TLI) (where >.90 indicates acceptable fit); and the standardized root mean square residual(SRMR) (where values as high as .08 are deemed acceptable). Nested model comparisons were evaluated using chi-square difference tests. We also used the criterion of not rejecting the null hypothesis of invariance when there is a change in CFI of less than .01, RMSEA of less than .015, and TLI of less than .01 (Chen, 2007; Cheung \& Rensvold, 2002; Vandenberg \& Lance, 2000).

\section{Results}

\section{Descriptive Statistics}

LDRR or GCRR self-identification of the participants strongly correlated with the distance relationship status measurement checks that we included $(r(456)=.80, p<.001)$. Table 1 provides a summary of the comparison of means for the main constructs (FBI, FBRSup, RelStab, and RelSati), as well as the other variables included in this study. On average, individuals in GCRR had higher Facebook intensity $(F B I)\left(M_{G C R R}=3.67, S D=0.69\right)$ than those in LDRR $\left(M_{L D R R}=3.47, S D=0.76 ; t(454)=-2.85, p=.005 ; d=0.28\right)$, Facebook relationship support (FBRSup) $\left(M_{G C R R}=3.16, S D=0.71\right.$ and $\left.M_{L D R R}=2.85, S D=0.80 ; t(454)=-4.15, p<.001, d=0.41\right)$, perceived relationship stability $\left(M_{G C R R}=6.41, S D=1.08\right.$ and $\left.M_{L D R R}=6.02, S D=1.46 ; t(212)=-2.82, p=.005 ; d=0.30\right)$ and perceived relationship satisfaction $\left(M_{G C R R}=4.43, S D=0.78\right.$ and $\left.M_{L D R R}=4.15, S D=0.92 ; t(454)=-3.33, p=.001, d=0.33\right)$.

The top five communication channels with their partner for those in LDRR were instant messaging, video calling, Facebook private communication, SMS, and phone calls and for those in GCRR were SMS, phone call, Facebook private communication, instant messaging, and Facebook public communication. Other social media, like Twitter and Instagram, were the least frequent forms of communication with partner for both groups. It appears that Facebook private communication with partner was the third preferred communication platform for both those in LDRR and GCRR. 


\begin{tabular}{|c|c|c|c|c|c|c|c|}
\hline & \multicolumn{2}{|c|}{ LDRR } & \multicolumn{2}{|c|}{ GCRR } & \multirow{2}{*}{$t$} & \multirow{2}{*}{$d f$} & \multirow{2}{*}{$d$} \\
\hline & $M$ & $S D$ & $M$ & $S D$ & & & \\
\hline \multicolumn{8}{|l|}{ Main variables: } \\
\hline $\mathrm{FBI}$ & 3.47 & 0.76 & 3.67 & 0.69 & $-2.85^{* *}$ & 454 & 0.28 \\
\hline FBRSup & 2.85 & 0.80 & 3.16 & 0.71 & $-4.15 * * *$ & 454 & 0.41 \\
\hline Rel Stability & 6.02 & 1.46 & 6.41 & 1.08 & $-2.82^{* *}$ & $212^{a}$ & 0.30 \\
\hline Rel Satisfaction & 4.15 & 0.92 & 4.43 & 0.78 & $-3.33 * *$ & 454 & 0.33 \\
\hline \multicolumn{8}{|l|}{ Covariates: } \\
\hline Length of Rel & 36.20 & 34.10 & 65.15 & 66.43 & $-6.14 * * *$ & 447 & 0.55 \\
\hline \multicolumn{8}{|c|}{ Frequency of communication with partner via: } \\
\hline Instant Message & 3.61 & 1.59 & 3.24 & 1.49 & $2.41^{*}$ & 454 & 0.24 \\
\hline Video call & 3.58 & 1.48 & 2.06 & 1.00 & $11.16^{* * *}$ & $201^{a}$ & 1.20 \\
\hline FB private & 3.45 & 1.51 & 3.52 & 1.23 & -0.47 & $230^{a}$ & 0.05 \\
\hline SMS & 3.42 & 1.49 & 4.03 & 1.11 & $-4.40 * * *$ & $214^{a}$ & 0.46 \\
\hline Phone & 3.12 & 1.49 & 3.77 & 1.02 & $-4.77 * * *$ & $203^{a}$ & 0.51 \\
\hline FB public & 2.65 & 1.25 & 2.75 & 1.07 & -0.81 & $189^{a}$ & 0.09 \\
\hline Email & 2.18 & 1.24 & 2.19 & 0.98 & -0.12 & $222^{a}$ & 0.01 \\
\hline Twitter \& Instagram & 1.90 & 1.21 & 1.93 & 1.17 & -0.21 & 443 & 0.03 \\
\hline
\end{tabular}

Notes. FBI-Facebook Intensity, FBRSup-Facebook relationship support, RelStab-relational stability, RelSati- relational satisfaction

${ }^{*} p<.05,{ }^{* *} p<.01, * * * p<.001$.

aEqual variances not assumed.

\section{Analysis of the Main Mediation Model}

We conducted invariance analyses using MPlus version 7 (Muthén \& Muthén, 2012) and maximum likelihood estimation on the baseline model (Figure 1) starting with configural invariance. The model showed an adequate fit to the data $\left(\chi^{2}=366.74 ; \chi^{2} / d f=\right.$ 1.76; $\mathrm{CFI}=.95 ; \mathrm{TLI}=.92 ; \mathrm{RMSEA}=.06 ; \mathrm{SRMR}=.06)$, demonstrating configural invariance. The model also demonstrated metric and scalar invariance (see Table 2), allowing for the comparison between the two groups (Chen, 2008; Kühne, 2013).

Table 2. Fit Indices for Invariance Tests.

\begin{tabular}{lccccccccccccc}
\hline Model & $\chi^{2}$ & $d f$ & $\chi^{2} / d f$ & RMSEA & CFI & TLI & SRMR & $\Delta \chi^{2}$ & $d f$ & $p$ & $\Delta R M S E A$ & $\Delta C F I$ & $\Delta T L I$ \\
\hline Model 1 & & & & & & & & & & & & \\
Configural & 366.74 & 208 & 1.76 & .06 & .95 & .92 & .06 & & & & & \\
Metric & 383.70 & 222 & 1.73 & .06 & .95 & .93 & .06 & 15.77 & 14 & .328 & .002 & .001 & .004 \\
Scalar & 405.35 & 236 & 1.72 & .06 & .94 & .93 & .07 & 21.09 & 14 & .099 & .000 & .002 & .002 \\
\hline With covariates included & & & & & & & & & & & \\
Model 2 & & & & & & & & & & & & & \\
Configural & 816.98 & 478 & 1.71 & .06 & .89 & .86 & .07 & & & & & \\
Model 3 & & & & & & & & & & & & & \\
Configural & 413.81 & 238 & 1.74 & .06 & .94 & .92 & .06 & & & & & & \\
Metric & 430.69 & 252 & 1.71 & .06 & .94 & .92 & .07 & 15.60 & 14 & .338 & .001 & .001 & .005 \\
Scalar & 452.51 & 266 & 1.70 & .06 & 0.94 & 0.92 & .07 & 21.27 & 14 & .095 & .000 & .002 & .001 \\
\hline
\end{tabular}

Figures 2 and 3 show the mediation models with the specified causal paths for LDRR and GCRR based on Model 1, respectively. The results showed that in both LDRR and GCRR, Facebook intensity predicted Facebook relationship support $(\beta$ LDRR $=.49, p<.001$; $\left.\beta_{\mathrm{GCRR}}=.59, p<.001\right)$, which in turn predicted perceptions of relationship satisfaction in both LDRR and GCRR ( $\beta$ LDRR $=.46, p<.001$; $\left.\beta_{G C R R}=.26, p=.007\right)$, and relationship stability only in LDRR ( $\left.\beta_{\text {LDRR }}=.52, p<.001\right)$. Although the associations of Facebook relationship support with perceived relationship satisfaction were significant in both LDRR and GCRR, the effect was significantly 
higher in LDRR than in GCRR $(z=2.27 ; p=.023)$. Moreover, Facebook intensity had a direct negative association with perceived relationship satisfaction in GCRR ( $\beta_{\mathrm{GCRR}}=-.26, p=.005$ ). Facebook intensity also had a significant direct negative effect on perceived relationship stability in LDRR ( $\beta$ LDRR $=-.23, p=.044)$. The results also showed that Facebook intensity had significant positive indirect effects on relationship satisfaction in both $\operatorname{LDRR}\left(\beta_{\mathrm{LDRR}}=.22, p=.008,95 \% \mathrm{BCa} \mathrm{Cl}[.06, .60]\right)$ and GCRR $\left(\beta_{\mathrm{GCRR}}=.16, p=.012,95 \%\right.$ $\mathrm{BCa} C l[.02, .37])$, and relationship stability in $\operatorname{LDRR}\left(\beta_{\mathrm{LDRR}}=.25, p=.005,95 \% \mathrm{BCa} \mathrm{Cl}[.07, .65]\right)$, but not in GCRR. ${ }^{1}$

Figure 2. The Mediation Model for the LDRR Group Presented with the Standardized Regression Coefficients of the Statistically Significant Paths.

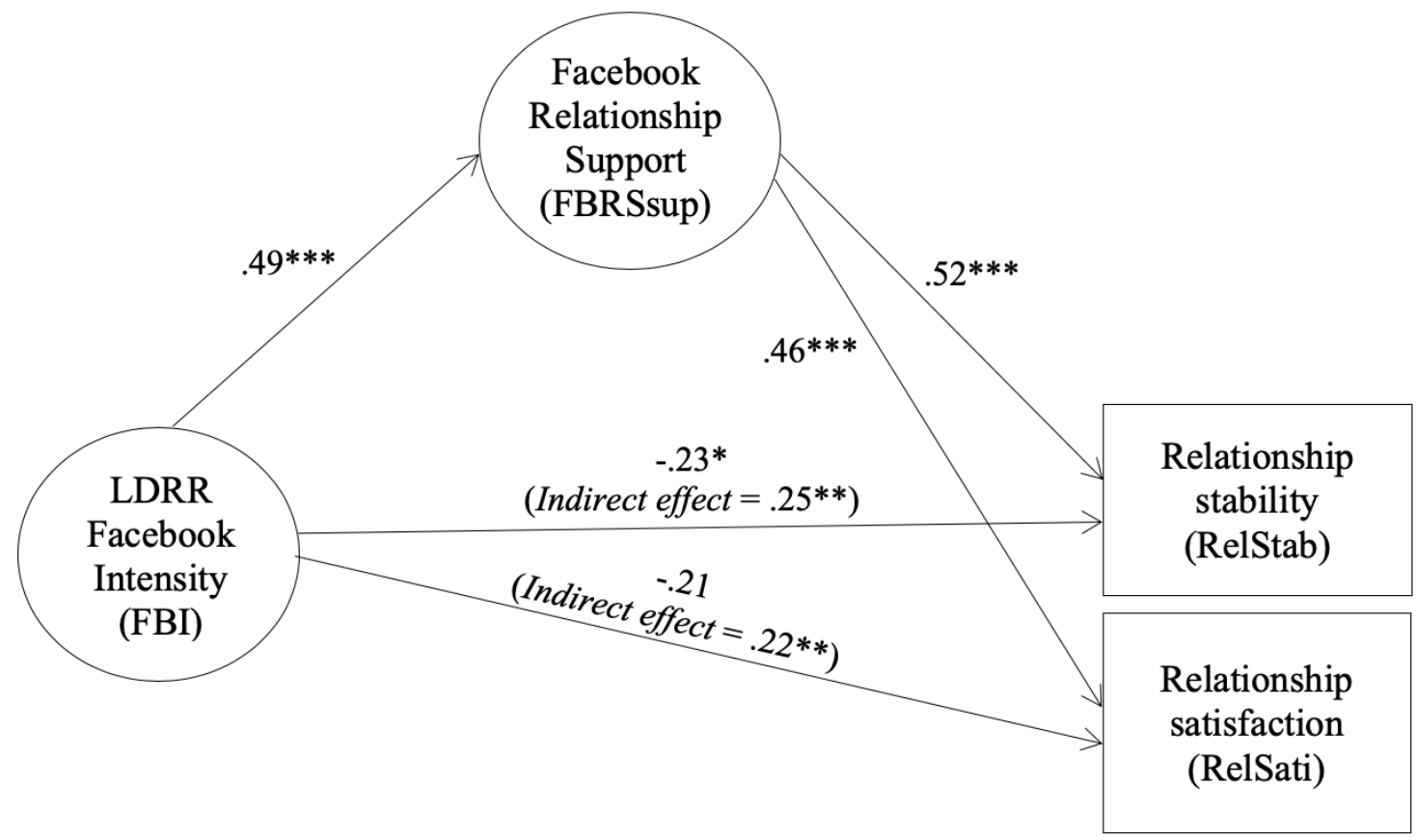

Notes. ${ }^{*} p<.05,{ }^{* *} p<.01,{ }^{* * *} p<.001$.

Indirect effect of LDRR-FBI on RelStab: $\beta=.25, p=.005,95 \% \mathrm{BCa} C \mathrm{Cl}[.07, .65]$.

Indirect effect of LDRR-FBI on RelSati: $B=.22, p=.008,95 \% \mathrm{BCa}$ Cl $[.06, .60]$

Figure 3. The Mediation Model for the GCRR Group Presented with the Standardized Regression Coefficients of the Statistically Significant Paths.

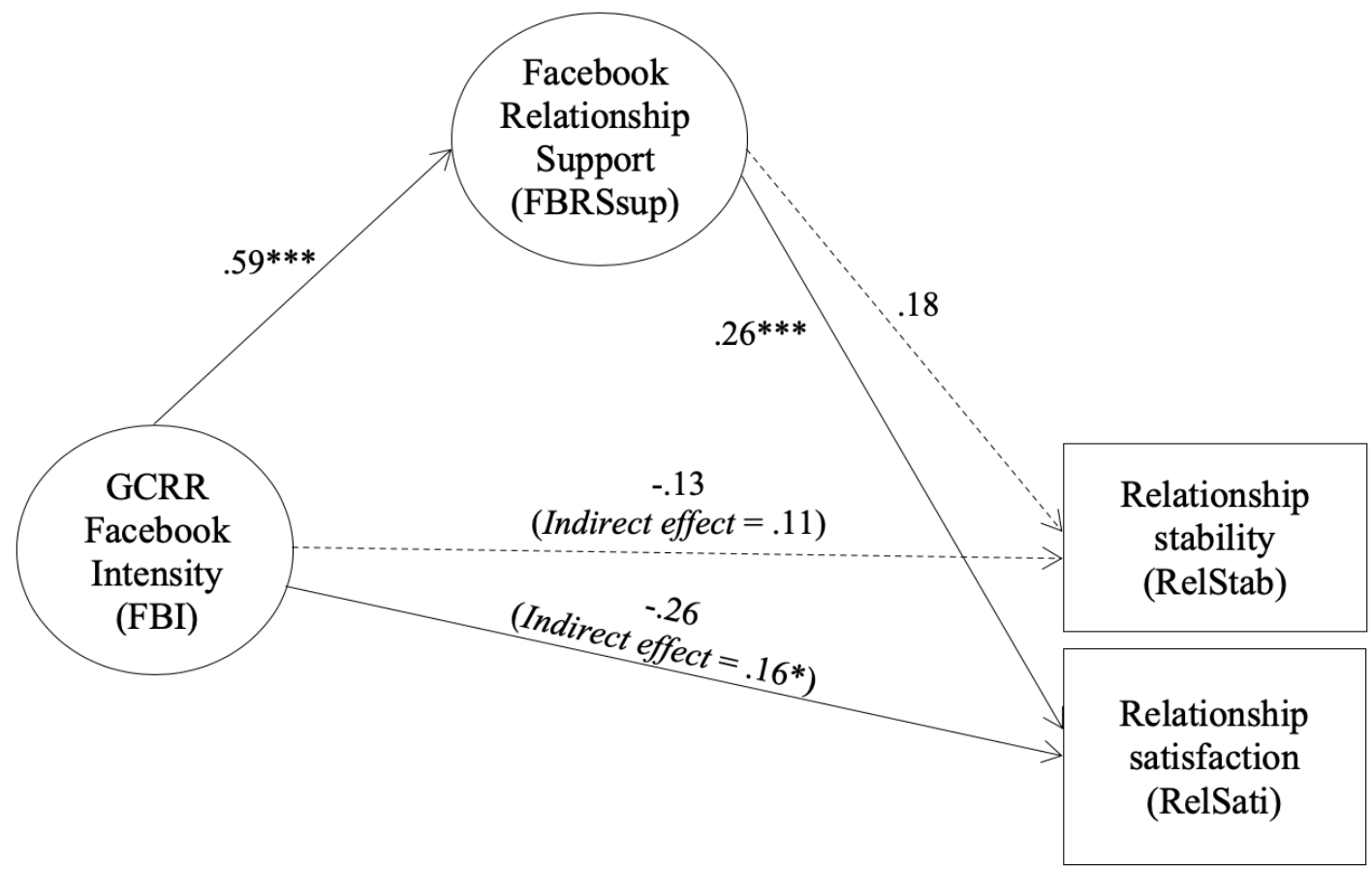

Notes. ${ }^{*} p<.05,{ }^{* *} p<.01,{ }^{* * *} p<.001$.

Indirect effect of GCRR-FBI on RelStab: $\beta=.11, p=.071,95 \% \mathrm{BCa}$ Cl $[-.02, .30]$.

Indirect effect of GCRR-FBI on RelSati: $\beta=.16, p=.012,95 \% \mathrm{BCa} C l[.02, .37]$ 
Next, we ran a model (Model 2) with the following covariates added to the baseline model: Gender, age, length of relationship, and each communication frequency with partner using phone, SMS, email, instant messaging, video calling, and Twitter and Instagram. The results showed poor fit to the data (see Table 2). To improve the fit, we tested a modified model (Model 3) with only video calling (i.e., Skype) as a covariate and excluded all others with non-significant paths. The ensuing model had a satisfactory fit $\left(\chi^{2}=410.74 ; \chi^{2} / d f=1.73 ; \mathrm{CFI}=.94 ; \mathrm{TLI}=.91 ; \mathrm{RMSEA}=.06 ;\right.$ SRMR $\left.=.06\right)$. The model also showed metric and scalar invariance (see Table 2).

With the inclusion of video calling in the model, the pattern of significant and non-significant direct and indirect causal paths in the model for LDRR and GCRR did not differ from Model 1 (see Table 3). The direct association between Facebook intensity and perceived relationship stability remained significant when video calling was accounted for ( $\left.\beta_{\operatorname{LDRR}}=-.25, p=.024\right)$. The results also showed that the frequency of communication with partner via video calling had opposite associations with relationship quality for LDRR and GCRR. In LDRR, video calling was positively associated with relationship satisfaction ( $\beta$ LDRR $=.22, p=.004)$ and stability $\left(\beta_{\text {LDRR }}=.26, p<.001\right)$. In GCRR, it was negatively associated with relationship satisfaction $\left(\beta_{\mathrm{GCRR}}=-.14, p=.014\right){ }^{2}$

Table 3. Comparison of the Standardized Parameter Estimates for Model 3.

\begin{tabular}{|c|c|c|c|c|c|c|}
\hline \multirow{2}{*}{ PATHS } & \multicolumn{2}{|c|}{ LDRR } & \multicolumn{2}{|c|}{ GCRR } & \multirow{2}{*}{$z$} & \multirow{2}{*}{$p$} \\
\hline & $\beta$ & $p$ & $\beta$ & $p$ & & \\
\hline \multicolumn{7}{|l|}{ Direct effects } \\
\hline FBI $\rightarrow$ FBRSup & .48 & .000 & .59 & .000 & -1.52 & .129 \\
\hline $\mathrm{FBI} \rightarrow$ RelStab & -.25 & .024 & -.13 & .147 & -1.22 & .223 \\
\hline $\mathrm{FBI} \rightarrow$ RelSati & -.22 & .062 & -.28 & .002 & 0.63 & .529 \\
\hline FBRSup $\rightarrow$ RelStab & .48 & .000 & .19 & .055 & 3.24 & .001 \\
\hline FBRSup $\rightarrow$ RelSati & .43 & .000 & .29 & .003 & 1.58 & .114 \\
\hline VidCall $\rightarrow$ FBRSup & .11 & .142 & .12 & .045 & -0.10 & .920 \\
\hline VidCall $\rightarrow$ RelStab & .26 & .000 & -.07 & .220 & 3.30 & .001 \\
\hline VidCall $\rightarrow$ RelSati & .22 & .004 & -.14 & .014 & 3.57 & .000 \\
\hline \multicolumn{7}{|l|}{ Indirect effects } \\
\hline $\mathrm{FBI} \rightarrow$ RelStab & .23 & .007 & .11 & .063 & 1.21 & .226 \\
\hline FBI $\rightarrow$ RelSati & .20 & .011 & .17 & .007 & 0.30 & .764 \\
\hline
\end{tabular}

Notes. FBI-Facebook Use Intensity, FBRSup-Facebook relationship support, RelStab-relational stability, RelSati-relational satisfaction, VidCall-Video call.

Confidence Intervals of the indirect effects:

Indirect effect of LDRR-FBI on RelStab: $\beta=.23,95 \% \mathrm{BCa} C \mathrm{Cl}[.06, .59]$

Indirect effect of LDRR-FBI on RelSati: $\beta=.20,95 \% \mathrm{BCa} C \mathrm{Cl}[.05, .56]$,

Indirect effect of GCRR-FBI on RelStab: $\beta=.11,95 \% \mathrm{BCa}$ Cl $[-.05, .31]$,

Indirect effect of GCRR-FBI on RelSati: $\beta=.17,95 \% \mathrm{BCa} C \mathrm{Cl}[.04, .40]$.

\section{Discussion}

Earlier studies using a social network perspective have shown that romantic relationships benefit from offline social network support (Cox et al., 1997; Felmlee, 2001). This study adds to existing literature by showing that network support could be extended and experienced on SNSs. We examined the proposition that SNSs use predicts access to SNSs network support which, in turn, predicts relationship quality in LDRR and GCRR. In this study, we focused on Facebook, the most popular SNS. We conceptualized Facebook use in this study as Facebook intensity which included not only duration of use and network size, but also integration of one's daily activities with the platform. This conceptualization is consistent with previous studies on Facebook use in relation to romantic relationships and social support (Billedo et al., 2015; Ellison et al., 2007; Hu et al., 2017; Vanden Abeele et al., 2018). The results showed that Facebook intensity per se was negatively associated with relationship quality. However, it was when users accessed relationship support from their Facebook networks that Facebook intensity indirectly contributed to positive relationship quality. Thus, Facebook could be relevant in relational maintenance because of its utility in marshaling relationship-related support from a couple's network, which we found to be beneficial for romantic relationships. 


\section{Facebook Intensity and Relationship Quality in LDRR and GCRR}

The results indicated that those in GCRR reported higher levels of Facebook intensity than those in LDRR. In a previous study comparing Facebook intensity in LDRR and GCRR, the opposite result was found (Billedo et al., 2015). Note, however, that the frequency of Facebook use specifically to communicate with one's partner (i.e., Facebook private and public communications with partner) did not differ between LDRR and GCRR groups. This is consistent with the findings of an earlier study, which indicated that Facebook communication frequency with a specified friend did not vary between long-distance and geographically-close friendships (Vitak, 2014). Taken together, these results imply that the levels of Facebook intensity might vary for LDRR and GCRR when used for general purposes, but not when they are used specifically to communicate with significant others. We suggest that subsequent studies should aim to replicate and validate these findings and examine their robustness.

We also found that GCRR participants reported higher levels of Facebook relationship support compared to LDRR participants. This could be because GCRR partners have more accessible (e.g., geographically co-located) social networks (offline or Facebook). In LDRR, one partner is away from most of the couple's established support network, and this might limit support in two ways (Weiner \& Hannum, 2013): First, people may be less likely to solicit support from a long-distance social network; and second, long-distance social networks cannot be as immediately and directly supportive as geographically-close social networks, "even with improved communication options to bridge the distance" (p.668).

Moreover, those in GCRR reported higher perceived relationship stability and satisfaction than those in LDRR. Most likely, the challenge of geographic separation is taking its toll among those in LDRR. LDRR often require more effort to maintain compared to GCRR (Aylor, 2003). Distance could be straining those in LDRR in keeping the relationship going and affecting their sense of satisfaction with their relationships (Mok et al., 2007).

\section{Facebook: A Double-Edged Sword for Romantic Relationships?}

This study advances theory by demonstrating a possible mechanism that could help clarify and disentangle the complex relation of Facebook use and relationship outcomes. Previous studies have not reached a consensus regarding the association of Facebook use and relationship outcomes (Clayton et al., 2013; Hand et al., 2013; Kirk, 2013; Muise et al., 2009; Utz \& Beukeboom, 2011). We found two possible opposing processes: First, when individuals accessed relationship-related support from their Facebook network, Facebook intensity could impact romantic relationships in a positive way. Second, Facebook intensity could have a direct negative impact on romantic relationship quality.

\section{The Value of Facebook}

Our study validates the findings of previous research that individuals (Ellison et al., 2007; Papacharissi \& Mendelson, 2008) and romantic relationships (Utz \& Beukeboom, 2011) could benefit from Facebook use via access to social capital and network support. We found that Facebook intensity was positively associated with Facebook relationship support. Moreover, we found that Facebook relationship support was positively associated with relationship stability among those in LDRR but not in GCRR. Facebook intensity also had an indirect positive effect on relationship stability among those in LDRR. These findings suggest that Facebook relationship support is less important for the survival of GCRR. For those in LDRR, Facebook relationship support could be critical because they have limited opportunities as a couple to engage in offline social activities and events with their shared network. These social experiences are often venues where network members are able to show and express their affirmation of couples' relational identities. Social affordances associated with Facebook intensity could be compensating for the limited face-to-face opportunities to experience such social processes in LDRR (Jiang \& Hancock, 2013; Dainton \& Aylor, 2002). On Facebook, LDRR have a venue to present relational links and mutual belonging that might encourage validating responses and behaviors from their network. These social processes are considered vital in the maintenance of romantic relationships (Felmlee, 2001; Tong \& Walther, 2011).

Access to Facebook relationship support was shown to be associated with greater relationship satisfaction in both LDRR and GCRR. Via Facebook, relationship partners may access relational information that contributes to more positive feelings towards their relationship (Billedo et al., 2015; Felmlee, 2001; Fox et al., 2013; Vitak, 2014). Having friends expressing their approval and emotional support, and having people to talk to and ask assistance from with regards to their partner could have facilitated relationship satisfaction. Note that although the effect of Facebook relationship support on satisfaction was significant for both LDRR and GCRR, the effect was significantly stronger in LDRR. This implies the relatively greater value of Facebook social support in LDRR than in GCRR. 


\section{The Threat of Facebook}

Our findings show that Facebook intensity was directly negatively associated with relationship stability in LDRR, suggesting that it may threaten the survival of LDRR. It could be that the use of Facebook, if it is not purposive nor partner/relationship-directed, distracts LDRR individuals from performing relationship maintenance behaviors on Facebook. The results suggest that the general, and not relationally targeted, Facebook use could diminish relationship stability (Burke \& Kraut, 2016; Verduyn et al., 2017). Among GCRR couples, Facebook intensity was not directly associated with relationship stability; there was also no mediation effect for Facebook intensity and relationship stability via Facebook relationship support. Together, these results imply that Facebook was not considered essential for the survival of GCRR.

In GCRR, Facebook intensity was negatively associated with relationship satisfaction. Previous studies among those in a romantic relationship from the general population have shown that Facebook use was associated with negative effects in the relationship (e.g., jealousy and suspicion) (Muise et al., 2009; Tokunaga, 2011; Utz \& Beukeboom, 2011). The findings of this study are consistent with previous research, demonstrating that higher levels of Facebook intensity in GCRR undermines positive feelings about the relationship. In contrast, Facebook intensity was not directly associated with relationship satisfaction in LDRR. It could be that for those in LDRR, feelings associated with Facebook intensity were more varied (e.g., positive and negative affects) (Utz \& Beukeboom, 2011). With limited face-to-face social interactions, this medium could function as a venue for diverse social experiences as a couple (Tong \& Walther, 2011).

Thus, our findings suggest that higher Facebook intensity could be detrimental to one's relationship. However, the indirect effects, accounting for relationship support, showed that higher Facebook intensity could be beneficial to one's relationship. Facebook intensity, via relationship support, increased relationship satisfaction in GCRR and LDRR; and stability in LDRR. Previous studies have shown that the active and targeted form of communication with significant others on SNS is associated with positive outcomes (e.g., higher social support, wellbeing), while the passive use of SNS is mostly associated with negative outcomes (Burke \& Kraut, 2016; Verduyn et al., 2017). In relation to this study, it appears that Facebook use, if used purposively for relationshiprelated activities, could be beneficial for one's sense of stability and satisfaction in the relationship.

\section{Concurrent Use of Communication Technologies}

Our findings also show that LDRR and GCRR couple members differed in their frequency of communication with specific channels when communicating with their partner. LDRR couple members used instant messaging (e.g., Whatsapp, Viber) and video calls (e.g., Skype) more than participants in GCRR. GCRR couple members used SMS and phone calls more than participants in LDRR. One possible reason for this might be the difference in costs for using these communication channels. Instant messaging and video calls are Internet-based communication channels and, for most people, are free as long as one is connected to the Internet. SMS and phone calls are free or relatively cheap if users are within the same geographic region but can be costly if long-distance. Another possible reason could be the differences in affordances that these communication platforms provide. For example, video calls, compared to SMS or phone calls, are channels with greater bandwidth. For those in LDRR, video calls were more preferred most likely because of the higher need for real time face-to-face/visual interactions with the partner, compared to those in GCRR.

Among the various communication platforms, we found that video calling had a relatively more significant impact on the model we proposed. In a previous study, Skype (a video calling app) was ranked as the most frequently used communication platform among LDRR couples (Kirk, 2013). In this study, we found that video calling is the second most used communication platform with partner in LDRR (while second least used in GCRR). Video calling had positive associations with relationship stability and satisfaction in LDRR. Considering limited face-to-face interactions, greater bandwidth platforms such as video calling were considered beneficial for romantic relationship quality. For instance, video calling provides couples in LDRR an opportunity to share presence despite geographic distance, and this contributes to their sense of intimacy and closeness (Neustaedter \& Greenberg, 2011).

In GCRR, video calling had a negative association with relationship satisfaction. This finding, along with the result that Facebook intensity was negatively associated with relationship satisfaction, suggests that the use of these communication technologies in GCRR might not necessarily help the relationship. This is a provocative idea considering previous propositions that communication technologies may play supplementary roles in GCRR (Rabby \& Walther, 2003; Tong \& Walther, 2011). Future studies should explore this idea further.

Our results demonstrate the relative importance of Facebook for relational maintenance compared with other communication technologies. These observations highlight the need for further investigations on the concurrent use and interplay of different communication technologies in romantic relationships (Caughlin \& Sharabi, 2013). 


\section{Limitations and Recommendations}

One of the limitations of this study is the sample size. We recommend for future studies to have a larger sample and a more balanced sampling of LDRR and GCRR participants in terms of number and time of measurement. With the relatively small sample size for LDRR participants, the results of this current study should be taken with caution. Other studies should replicate these findings in larger samples to examine their robustness. Additionally, although we dealt with the issue of measurement invariance, we cannot fully isolate potential time-related confounds, especially since Facebook features and affordances, as well as other communication technologies evolve rapidly. It is also recommended for future studies to test the validity and reliability of the Facebook Relationship Support scale. Additionally, given the cross-sectional and correlational nature of this study, directionality cannot be truly established. We argued the proposed model based on well-founded theoretical expectations (Ellison et al., 2007; Felmlee, 2001; Keneski \& Loving, 2014; Papacharissi \& Mendelson, 2008; Utz \& Breuer, 2017). However, the model testing we conducted only made it possible to see whether a set of results is consistent with a causal model. Thus, future studies should address the question of directionality/bidirectionality in their design. We recommend the use of longitudinal and experimental designs to test the validity of our findings. Moreover, future research including both relationship partners and do a dyadic level analysis would be promising. This design could contribute to a more nuanced characterization of LDRR (e.g., those who leave vs. those who stay).

This current study was limited by measuring only the positive aspects of network influence. We did not look at the "dark" side of network influence via Facebook (e.g., supplying negative information about the partner, expressing disapproval about the relationship) (Felmlee, 2001). Moreover, we focused on Facebook relationship support from the perspective of those in romantic relationships, and did not include the point of view of social network members. Keneski and Loving (2014) underscored the relevance of getting social network members' reports of actual relationship appraisal and support to broaden the understanding of this social dynamic. We recommend that these conceptualizations of network roles be considered in future studies.

In this study, relationship support received from one's in-person social network was not included as a covariate. It is possible that those giving support online are also giving support in person. It is recommended that future research accounts for this factor. We also suggest that future research includes demographic factors such as ethnicity, socioeconomic status, and country of residence as control variables. Adding these covariates would provide a more comprehensive understanding of the model.

We focused on Facebook as an exemplar for SNSs because of its popularity and its relevance in relationship maintenance based on previous studies (Billedo et al., 2015; Dainton \& Stokes, 2015). Future studies should investigate other SNSs to examine the generalizability of our findings. In this study, for instance, the use of Twitter and Instagram for dyadic communication (i.e., between partners) was minimal. Given the rate by which technology usage evolves, future studies may consider these possible changes, such as the use of Twitter and Instagram for communication with one's romantic partner for relationship maintenance.

There were a few single-item measures used in this study (e.g., frequency of communication with partner using Facebook and other communication channels, perceived relationship stability, perceived relationship satisfaction). The use of single-item measures does not allow the investigation of the multidimensionality of the constructs (van der Linden \& Rosenthal, 2016). Future research should investigate the comparability of these single-item measurements with the use of multi-item scales for the same constructs (Konrath et al., 2014; van der Linden \& Rosenthal, 2016).

\section{Conclusions}

Facebook could be a double-edged sword for romantic relationships. Facebook intensity could have a detrimental impact on romantic relationships. However, Facebook intensity could be beneficial via social affordances that allow couples to maintain a network supportive of their relationship. For those in LDRR, Facebook intensity, via relationship support, is relatively more important for relationship stability and satisfaction compared to those in GCRR. Our study contributes to the existing literature by elucidating the complex role of Facebook in the maintenance of romantic relationships.

\section{Footnotes}

1. For mean comparisons, we inspected the latent means and found that they lead to the same conclusions as the raw composite means reported in Table 1.

2. Due to the relatively small sample in LDRR, we validated our findings by conducting a series of simple mediation analyses using Hayes' PROCESS (Hayes et al., 2017). We found similar patterns of results. 


\section{Acknowledgement}

This research was supported by the System Faculty Development Program of the University of the Philippines awarded to Cherrie Joy Billedo.

\section{References}

Ahmad, I. (2019, January 1). The most popular social media platforms of 2019. Digital Information World. https://www.digitalinformationworld.com/2019/01/most-popular-global-social-networks-apps-infographic.html

Albrecht, T. L., \& Adelman, M. B. (1987). Communicating social support. Sage.

Arriaga, X. B., Goodfriend, W., \& Lohmann, A. (2004). Beyond the individual: Concomitants of closeness in the social and physical environment. In D. Mashek \& A. Aron (Eds.), Handbook on relationship closeness (pp. 287-303). Lawrence Erlbaum.

Aylor, B. A. (2003). Maintaining long-distance relationships. In D. J. Canary \& M. Dainton (Eds.), Maintaining relationships through communication: Relational, contextual, and cultural variations (pp. 127-139). Lawrence Erlbaum.

Billedo, C. J., Kerkhof, P., \& Finkenauer, C. (2015). The use of social network sites for relationship maintenance in long-distance and geographically-close romantic relationships. Cyberpsychology, Behavior, and Social Networking, 18(3), $152-157$. https://doi.org/10.1089/cyber.2014.0469

Burke, M., \& Kraut, R. E. (2016). The relationship between Facebook use and well-being depends on communication type and tie strength. Journal of Computer-Mediated Communication, 21(4), 265-281. https://doi.org/10.1111/jcc4.12162

Canary, D. J., \& Stafford, L. (1992). Relational maintenance strategies and equity in marriage. Communication Monographs, 59(3), 243-267. https://doi.org/10.1080/03637759209376268

Caughlin, J. P., \& Sharabi, L. L. (2013). A communicative interdependence perspective of close relationships: The connections between mediated and unmediated interactions matter. Journal of Communication, 63(5), 873-893.

https://doi.org/10.1111/jcom.12046

Chen, F. F. (2007). Sensitivity of goodness of fit indexes to lack of measurement invariance. Structural Equation Modeling: $A$ Multidisciplinary Journal, 14(3), 464-504. https://doi.org/10.1080/10705510701301834

Chen, F. F. (2008). What happens if we compare chopsticks with forks? The impact of making inappropriate comparisons in cross-cultural research. Journal of Personality and Social Psychology, 95(5), 1005-1018. https://doi.org/10.1037/a0013193

Cheung, G. W., \& Rensvold, R. B. (2002). Evaluating goodness-of-fit indexes for testing measurement invariance. Structural Equation Modeling: A Multidisciplinary Journal, 9(2), 233-255. https://doi.org/10.1207/S15328007SEM0902_5

Clayton, R. B., Nagurney, A., \& Smith, J. R. (2013). Cheating, breakup, and divorce: Is Facebook use to blame? Cyberpsychology, Behavior, and Social Networking, 16(10), 717-720. https://doi.org/10.1089/cyber.2012.0424

Cox, C. L., Wexler, M. O., Rusbult, C. E., \& Gaines, S. O. Jr. (1997). Prescriptive support and commitment processes in close relationships. Social Psychology Quarterly, 60(1), 79-90. https://doi.org/10.2307/2787013

Dainton, M., \& Aylor, B. (2001). A relational uncertainty analysis of jealousy, trust, and maintenance in long-distance versus geographically close relationships. Communication Quarterly, 49(2), 172-188. https://doi.org/10.1080/01463370109385624

Dainton, M., \& Aylor, B. (2002). Routine and strategic maintenance efforts: Behavioral patterns, variations associated with relational length, and the prediction of relational characteristics. Communication Monographs, 69(1), 52-66.

https://doi.org/10.1080/03637750216533

Dainton, M., \& Stokes, A. (2015). College students' relationships on Facebook: Linking the gratification for maintenance to Facebook maintenance activity and the experience of jealousy. Communication Quarterly, 63(4), 365-383.

https://doi.org/10.1080/01463373.2015.1058283 
Ellison, N., Steinfield, C., \& Lampe, C. (2007). The benefits of Facebook "friends:" Social capital and college students' use of online social network sites. Journal of Computer-Mediated Communication, 12(4), 1143-1168. https://doi.org/10.1111/j.1083-

6101.2007.00367.x

Ellison, N., Vitak, J., Gray, R., \& Lampe, C. (2014). Cultivating social resources on social network sites: Facebook relationship maintenance behaviors and their role in social capital processes. Journal of Computer-Mediated Communication 19(4), 855870. https://doi.org/10.1111/jcc4.12078

Emery, L. F., Muise, A., Alpert, E., \& Le, B. (2015). Do we look happy? Perceptions of romantic relationship quality on Facebook. Personal Relationships, 22(1), 1-7. https://doi.org/10.1111/pere.12059

Felmlee, D. H. (2001). No couple is an island: A social network perspective on dyadic stability. Social Forces, 79(4), $1259-1287$. https://doi.org/10.1353/sof.2001.0039

Fox, J., \& Warber, K. M. (2013). Social networking sites in romantic relationships: Attachment, uncertainty, and partner surveillance on Facebook. Cyberpsychology, Behavior, and Social Networking, 17(1), 3-7.

https://doi.org/10.1089/cyber.2012.0667

Fox, J., Warber, K. M., \& Makstaller, D. C. (2013). The role of Facebook in romantic relationship development: An exploration of Knapp's relational stage model. Journal of Social and Personal Relationships, 30(6), 771-794.

https://doi.org/10.1177/0265407512468370

Hand, M. M., Thomas, D., Buboltz, W. C., Deemer, E. D., \& Buyanjargal, M. (2013). Facebook and romantic relationships: Intimacy and couple satisfaction associated with online social network use. Cyberpsychology, Behavior, and Social Networking, 16(1), 813. https://doi.org/10.1089/cyber.2012.0038

Hayes, A. F., Montoya, A. K., \& Rockwood, N. J. (2017). The analysis of mechanisms and their contingencies: PROCESS versus structural equation modeling. Australasian Marketing Journal (AMJ), 25(1), 76-81. https://doi.org/10.1016/j.ausmj.2017.02.001

Hendrick, S. S. (1988). A generic measure of relationship satisfaction. Journal of Marriage and Family, 50(1), 93-98.

https://doi.org/10.2307/352430

Hu, X., Kim, A., Siwek, N., \& Wilder, D. (2017). The Facebook paradox: Effects of Facebooking on individuals' social relationships and psychological well-being. Frontiers in Psychology, 8, Article 87. https://doi.org/10.3389/fpsyg.2017.00087

Jackson, J. B., Miller, R. B., Oka, M., \& Henry, R. G. (2014). Gender differences in marital satisfaction: A meta-analysis. Journal of Marriage and Family, 76(1), 105-129. https://doi.org/10.1111/jomf.12077

Jiang, L. C., \& Hancock, J. T. (2013). Absence makes the communication grow fonder: Geographic separation, interpersonal media, and intimacy in dating relationships. Journal of Communication, 63(3), 556-577. https://doi.org/10.1111/jcom.12029

Keneski, E., \& Loving, T. J. (2014). Network perceptions of daters' romances. In C. R. Agnew (Ed.), Social influences on romantic relationships: Beyond the dyad (pp. 126-147). Cambridge University Press.

Kirk, A. (2013). The effect of newer communication technologies on relationship maintenance and satisfaction in long distanced relationships. Pepperdine Journal of Communication Research, 1, Article 2.

http://digitalcommons.pepperdine.edu/pjcr/vol1/iss1/2

Knobloch, L. K., \& Solomon, D. H. (1999). Measuring the sources and content of relational uncertainty. Communication Studies, 50(4), 261-278. https://doi.org/10.1080/10510979909388499

Konrath, S., Meier, B. P., \& Bushman, B. J. (2014). Development and validation of the Single Item Narcissism Scale (SINS). PLoS ONE, 9(8), Article e103469. https://doi.org/10.1371/journal.pone.0103469

Kühne, R. (2013). Testing measurement invariance in media psychological research. Journal of Media Psychology, 25(4), 153159. https://doi.org/10.1027/1864-1105/a000096

Mikal, J., Rice, R. E., Abeyta, A., \& De Vilbiss, J. (2013). Transition, stress and computer-mediated social support. Computers in Human Behavior, 29(5), A40-A53. http://dx.doi.org/10.1016/j.chb.2012.12.012 
Mok, D., Wellman, B., \& Basu, R. (2007). Did distance matter before the Internet? Interpersonal contact and support in the 1970s. Social Networks, 29(3), 430-461. https://doi.org/10.1016/j.socnet.2007.01.009

Muise, A., Christofides, E., \& Desmarais, S. (2009). More information than you ever wanted: Does Facebook bring out the greeneyed monster of jealousy? CyberPsychology \& Behavior, 12(4), 441-444. https://doi.org/10.1089/cpb.2008.0263

Muthén, L. K., \& Muthén, B. O. (2012). Mplus user's guide (7th ed.). Muthén \& Muthén.

Neustaedter, C., \& Greenberg, S. (2011). Intimacy in long-distance relationships over video chat (Report No. 2011-1014-26). http://citeseerx.ist.psu.edu/viewdoc/download?doi=10.1.1.228.3379\&rep=rep1\&type=pdf

Papacharissi, Z., \& Mendelson, A. (2008). Toward a new(er) sociability: Uses, gratifications, and social capital on Facebook [Paper presentation]. Internet Research Conference, Copenhagen, Denmark.

http://zizi.people.uic.edu/Site/Research_files/NewerSociabilityMediaPerspectives.pdf

Papp, L. M., Danielewicz, J., \& Cayemberg, C. (2012). “Are we Facebook official?” Implications of dating partners' Facebook use and profiles for intimate relationship satisfaction. Cyberpsychology, Behavior, and Social Networking, 15(2), 85-90.

https://doi.org/10.1089/cyber.2011.0291

Pistole, M. C., \& Roberts, A. (2011). Measuring long-distance romantic relationships: A validity study. Measurement and Evaluation in Counseling and Development, 44(2), 63-76. https://doi.org/10.1177/0748175611400288

Rabby, M. K., \& Walther, J. B. (2003). Maintaining on-line relationships. In D.J. Canary \& M. Dainton (Eds.), Maintaining relationships through communication: Relational, contextual, and cultural variations (pp. 141-162). Lawrence Erlbaum.

Ruffieux, M., Nussbeck, F. W., \& Bodenmann, G. (2014). Long-term prediction of relationship satisfaction and stability by stress, coping, communication, and well-being. Journal of Divorce \& Remarriage, 55(6), 485-501.

https://doi.org/10.1080/10502556.2014.931767

Rusbult, C. E., \& Buunk, B. P. (1993). Commitment processes in close relationships: An interdependence analysis. Journal of Social and Personal Relationships, 10(2), 175-204. https://doi.org/10.1177/026540759301000202

Saslow, L. R., Muise, A., Impett, E. A., \& Dubin, M. (2013). Can you see how happy we are? Facebook images and relationship satisfaction. Social Psychological and Personality Science, 4(4), 411-418. https://doi.org/10.1177/1948550612460059

Shafer, K., Jensen, T. M., \& Larson, J. H. (2014). Relationship effort, satisfaction, and stability: Differences across union type. Journal of Marital and Family Therapy, 40(2), 212-232. https://doi.org/10.1111/jmft.12007

Sinclair, H. C., Hood, K. B., Wright, B. L. (2014). Revisiting the Romeo and Juliet effect (Driscoll, Davis, \& Lipetz, 1972): Reexamining the links between social network opinions and romantic relationship outcomes. Social Psychology, 45(3), 170-178. http://dx.doi.org/10.1027/1864-9335/a000181

Stafford, L. (2005). Maintaining long-distance and cross-residential relationships. Lawrence Erlbaum.

Stafford L., \& Canary, D. J. (1991). Maintenance strategies and romantic relationship type, gender, and relational characteristics. Journal of Social and Personal Relationships, 8(2), 217-242. https://doi.org/10.1177/0265407591082004

Tokunaga, R. S. (2011). Social networking site or social surveillance site? Understanding the use of interpersonal electronic surveillance in romantic relationships. Computers in Human Behavior, 27(2), 705-713.

https://doi.org/10.1016/j.chb.2010.08.014

Tong, S. T., \& Walther, J. B. (2011). Relational maintenance and computer-mediated communication. In K. B. Wright \& L. M. Webb (Eds.), Computer-mediated communication in personal relationships (pp. 98-118). Peter Lang Publishing.

Utz, S., \& Beukeboom, C. J. (2011). The role of social network sites in romantic relationships: Effects on jealousy and relationship happiness. Journal of Computer-Mediated Communication, 16(4), 511-527. https://doi.org/10.1111/j.1083-6101.2011.01552.x

Utz, S., \& Breuer, J. (2017). The relationship between use of social network sites, online social support, and well-being: Results from a 6-wave longitudinal study. Journal of Media Psychology, 29(3), 115-125. https://doi.org/10.1027/1864-1105/a000222 
Van de Schoot, R., Lugtig, P., \& Hox. J. (2012). A checklist for testing measurement invariance. European Journal of

Developmental Psychology, 9(4), 486-492. https://doi.org/10.1080/17405629.2012.686740

van der Linden, S., \& Rosenthal, S. A. (2016). Measuring narcissism with a single question? A replication and extension of the Single-Item Narcissism Scale (SINS). Personality and Individual Differences, 90, 238-241.

https://doi.org/10.1016/j.paid.2015.10.050

Vanden Abeele, M. M. P., Antheunis, M. L., Pollmann, M. M. H., Schouten, A. P., Liebrecht, C. C., van der Wijst, P. J., van Amelsvoort, M. A. A., Bartels, J., Krahmer, E. J., \& Maes, F. A. (2018). Does Facebook use predict college students' social capital? A replication Of Ellison, Steinfield, and Lampe's (2007) study using the original and more recent measures of Facebook use and social capital, Communication Studies, 69(3), 272-282. https://doi.org/10.1080/10510974.2018.1464937

Vandenberg, R. J., \& Lance, C. E. (2000). A review and synthesis of the measurement invariance literature: Suggestions, practices, and recommendations. Organizational Research Methods, 3(1), 4-70. https://doi.org/10.1177/109442810031002

Verduyn, P., Ybarra, O., Résibois, M., Jonides, J., \& Kross, E. (2017). Do social network sites enhance or undermine subjective well-being? A critical review. Social Issues and Policy Review, 11(1), 274-302. https://doi.org/10.1111/sipr.12033

Visser, M., Finkenauer, C., Schoemaker, K., Kluwer, E., van der Rijken, R., van Lawick, J., Bom, H., de Schipper, J. C., LamersWinkelman, F. (2017). I'll never forgive you: High-conflict divorce, social network, and forgiveness. Journal of Child and Family Studies, 26(11), 3055-3066. https://doi.org/10.1007/s10826-017-0821-6

Vitak, J. (2014). Facebook makes the heart grow fonder: Relationship maintenance strategies among geographically dispersed and communication-restricted connections. In CSCW '14: Proceedings of the 17th ACM Conference on Computer Supported Cooperative Work and Social Computing (pp. 842-853). ACM. https://doi.org/10.1145/2531602.2531726

Weiner, A. S. B., \& Hannum, J. W. (2013). Differences in the quantity of social support between geographically close and longdistance friendships. Journal of Social and Personal Relationships, 30(5), 662-672. https://doi.org/10.1177/0265407512465997

\section{Appendices}

\section{Appendix A. Facebook Use Intensity Scale (FBI)}

Instructions: This section is about your Facebook use in general.

Please indicate to which extent do you agree with each statement $(1=$ strongly disagree $2=$ disagree $3=$ neutral $4=$ agree $5=$ strongly agree)*

1. Facebook is part of my everyday activity

2. I am proud to tell people I'm on Facebook

3. Facebook has become part of my daily routine

4. I feel out of touch when I haven't logged onto Facebook for a while

5. I feel I am part of the Facebook community

6. I would be sorry if Facebook shut down

7. About how many total Facebook friends do you have? $0=10$ or less, $1=11-50,2=51-100,3=101-150,4=151-200,5$ $=201-250,6=251-300,7=301-400,8=$ more than $400 * *$

8. In the past week, on average, approximately how much time PER DAY have you spent actively using Facebook? $1=$ less than 1 hour, 2 = 1-2hours, $3=2-4$ hours, $4=4-6$ hours, $5=$ more than 6 hours

*Unless provided, response categories ranged from 1 = strongly disagree to 5 = strongly agree.

**Individual items were first standardized before taking an average to create scale due to differing item scale ranges. 


\section{Appendix B. Facebook Relationship Support Scale (FBRSup)}

Instructions: In answering the next set of questions, please think about your romantic partner and your Facebook contacts like friends and family. Please indicate the extent to which you think you agree to each statement by using the following scale: ( $1=$ strongly disagree 2 = disagree 3 = neutral $4=$ agree $5=$ strongly agree)

Approval/Emotional support

1. There is someone I talk to about my romantic partner on Facebook.

2. Friends and/or family post positive comments on Facebook status updates/pictures my partner and I are both in.

Instrumental support

3. I am able to provide help when my partner is in need by asking the assistance of our common Facebook contacts.

4. My partner gets in touch with our shared Facebook contacts so they can help me when I need help/support.

Informational support

5. When I am having difficulties communicating with my partner, I approach friends and/or family via Facebook for help.

6. I become aware of my partner's activities via our Facebook friends' posts.

Embeddedness support

7. I feel that my romantic partner and I are a part of a group on Facebook who share our attitudes and beliefs.

8. My partner and I share common Facebook contacts who are supportive of our relationship. 


\section{Correspondence to:}

Cherrie Joy Billedo

Department of Communication Science, University of Amsterdam

Amsterdam Roeterseilandcampus, gebouw C

Nieuwe Achtergracht 166

1018 WV Amsterdam

The Netherlands

Email: c.j.billedo(a)uva.nl

Editorial record: First submission received on September 8, 2019. Revisions received on March 14, 2020 and April $30,2020$.

Accepted for publication on May 4, 2020.

Editor in charge: Lenka Dedkova

\section{About Authors}

Cherrie Joy Billedo, Ph.D. (c.j.billedo(at)uva.nl) is a lecturer at the department of Communication Science, University of Amsterdam, The Netherlands. She was formerly a member of the faculty of the department of Psychology, University of the Philippines. Her recent research focuses on social media use, social support, psychological and socio-cultural adjustment, as well as relationship maintenance of migrants.

Peter Kerkhof, Ph.D. (p.kerkhof(at)vu.nl) is a Professor in Social Media at the department of Communication Science and vice dean of education at the Faculty of Social Sciences at VU University Amsterdam, The Netherlands. His research focuses on both the individual use of online media, and the relation between individuals and organizations in online environments.

Catrin Finkenauer, Ph.D. (c.finkenauer(at)uu.nl) is a Professor of Interdisciplinary Social Sciences, and currently holds the chair in Interdisciplinary Social Sciences: Youth Studies at Utrecht University, The Netherlands. Her research focuses on interpersonal dynamics and examines how relationship partners influence each other. She is interested in parent-child relationships, intimate relationships, and friendships. 